\title{
A anemia falciforme como problema de Saúde Pública no Brasil *
}

\author{
The sickle cell disease as a Public Health problem in Brazil
}

\author{
Roberto B. de Paiva e Silva**, Antonio S. Ramalho**, Roosevelt M. S. Cassorla***
}

\begin{abstract}
PATVA e SILVA, R. B. de et al. A anemia falciforme como problema de Saúde Pública no Brasil. Rev. Saúde Pública, 27: 54-8, 1993. Apesar de a anemia falciforme ser a doença hereditária de maior prevalência no Brasil, a literatura nacional carece de investigações a respeito dos seus aspectos de Saúde Pública. Investigou-se a realidade vivida por 80 pacientes adultos ( 49 mulheres e 31 homens) com diagnóstico de anemia falciforme, seguidos regularmente em centro hematológico. $O$ diagnóstico tardio da doença foi um dos principais aspectos detectados na casuística examinada. Observou-se que a problemática maior do paciente adulto com a anemia falciforme está centrada nos aspectos econômicos, sobretudo na falta de oportunidades profissionais, apesar de os mesmos poderem participar do mercado de trabalho, desde que estejam recebendo tratamento médico adequado e exerçam funções compatíveis com as suas limitações e potencialidades. A orientação psicoterapêutica teve uma grande aceitação pelos pacientes, sem diferença significativa entre os sexos. Concluiu-se haver necessidade da implantação de programas comunitários de diagnóstico precoce e de orientação médica, social e psicológica dos doentes com a anemia falciforme no Brasil, bem como de aconselhamento genético não diretivo dos casais de heterozigotos com 0 traço falciforme.
\end{abstract}

Descritores: Anemia falciforme, epidemiologia. Qualidade de vida.

\section{Introduçăo}

A anemia falciforme, expressão clínica da homozigose do gene da hemoglobina S, é uma anomalia genética importante no Brasil, sobretudo nas regiőes que receberam maciços contingentes de escravos africanos. De fato, como comenta Rama$l^{1} 0^{13}$, ela é a doença hereditária de maior prevalência no país, afetando cerca de $0,1 \%$ a $0,3 \%$ da população negróide, sendo observada, também, em decorrência da alta taxa de miscigenação, em parcela cada vez mais significativa da população caucasóide brasileira. A falcização das hemácias por

* Trabalho baseado em parte da Dissertação de Mestrado: "Alguns aspectos psicossociais da anemia falciforme no Brasil. A percepção dos pacientes, bem como dos geneticistas e hematologistas, a respeito da doença", apresentada pelo primeiro autor, com a orientaçăo dos demais autores, à Faculdade de Ciências Médicas da UNICAMP, em 1992.

* Departarnento de Genética Médica da Faculdade de Ciências Médicas da Universidade Estadual de Campinas (UNICAMP) - Campinas, SP - Brasil.

* * Departamento de Psicologia Médica e Psiquiatria da Faculdade de Ciências Médicas da UNICAMP.

Separatas/Reprints: R. B. de Paiva e Silva - Caixa Postal 6111 - 13081-970 - Campinas, SP - Brasil.

Edição subvencionada pela FAPESP. Processo Medicina 93/ 0208-5. ela determinada, além de causar anemia hemolítica crônica, ainda é responsável pela obstrução de vasos sanguíneos, com crises de dor, infartamento e necrose em diversos órgãos, como ossos e articulaçðes, baço, pulmões, rins e outros ${ }^{16,17}$. Trata-se, portanto, de uma doença crônica, incurável, embora tratável, e que geralmente traz alto grau de sofrimento aos seus portadores, que merecem atenção especial do ponto de vista médico, genético e psicossocial ${ }^{13,16,17,20,22}$.

Embora a anemia falciforme tenha sido bastante estudada no Brasil em termos de frequência populacional $1,11,15,23$ e de manifestações clínicas $^{7}, 13,24$, os seus aspectos de saúde pública têm sido pouco enfatizados no Brasil. O presente trabalho visa a fornecer uma contribuição nesse sentido, discutindo a realidade vivida por uma amostra de pacientes atendidos no Hemocentro da Universidade Estadual de Campinas (UNICAMP).

\section{Casuistica e Método}

Foram entrevistados 80 pacieness (49 do sexo feminino e 31 do sexo masculino), com idades entre 18 e 44 anos (média de 25 anos e desvio padrão de 7 anos), seguidos há pelo menos um ano no Hemocentro da UNICAMP, com o diagnóstico clínico e laboratorial de anemia falciforme. 
Foram utilizados o método clínico ${ }^{19} \mathrm{e}$ o método epidemiológico-descritivo $0^{5}$, em entrevistas semiestruturadas realizadas entre os anos de 1986 e 1991.

Os pacientes foram convidados a participar dessas entrevistas, respeitando-se sempre a sua disposição para as mesmas, bem como a sua disponibilidade de tempo. As sessðes tiveram a duração aproximada de $60 \mathrm{~min}$., sendo realizadas à parte da consulta médica, em uma sala onde os pacientes pudessem ter privacidade e tranqüilidade. Os dados de cada paciente foram obtidos em um número mínimo de cinco sessōes (5 h de entrevistas).

As análises estatísticas foram realizadas por microcomputador, fazendo-se uso do programa Microstat $^{2}$, para comparação de proporçøes pelo teste do $X^{2}$.

\section{Resultados}

Dentre os 80 pacientes entrevistados, 55 (69\%) haviam sido diagnosticados como portadores da anemia falciforme há menos de 5 anos, $16(20 \%)$ entre 5 e 15 anos e $9(11 \%)$ há mais de 15 anos. Em 90\% da amostra, o diagnóstico havia sido estabelecido por ocasião do seu encaminhamento a algum setor do Hospital de Clínicas da UNICAMP, recebendo até então tratamento apenas sintomático para a dor.

O nível socioeconômico da casuística examinada revelou-se extremamente baixo, com uma renda per capita inferior a um salário mínimo e meio (o que equivalia a cerca de 70 dólares em agosto de 1992) em $85 \%$ dos pacientes. Dentre esses, 5 (6\%) eram analfabetos, $67(84 \%)$ possuiam o primeiro grau completo (6\%) ou incompleto $(78 \%) \mathrm{e}$ $7(10 \%)$ possuíam o segundo grau completo $(6 \%)$ ou incompleto (4\%).
Dentre os dados culturais da amostra, sobressaíram o uso regular de benzimentos por $38(48 \%)$ pacientes e a procura de curandeiros por 31 (39\%). A religião católica predominou na casuística examinada (80\%), seguida da evangélica (19\%) e da espírita (1\%).

$\mathrm{Na}$ Tabela são apresentados alguns dados ilustrativos da realidade vivida pelos pacientes entrevistados no presente trabalho.

Como é possível verificar, a interferência da doença na vida escolar foi referida por 23 pacientes $(28,7 \%)$, sem diferença significativa entre os sexos $\left(X^{2}(1)=0,94 ; P=33 \%\right)$. Já a interferência da anemia falciforme na profissão foi referida por 50 pacientes $(62,5 \%)$, também sem diferença significativa entre os sexos $\left(\mathrm{X}^{2}(1)=1,54 ; \mathrm{P}=\right.$ $21,3 \%$ ). Já no que se refere à dependência financeira total, observou-se uma diferença significativa entre os sexos, já que ela foi observada em $32,2 \%$ dos homens e em $81,6 \%$ das mulheres $\left(X^{2}\right.$ $(1)=19,75 ; \mathrm{P}<0,1 \%)$. Dentre os 80 pacientes entrevistados, $34(43 \%)$ trabalhavam regularmente $\mathrm{e}$ $9(11 \%)$ esporadicamente.

Dentre os 80 pacientes, 30 eram casados $(37,5 \%), 22$ dos quais $(73,3 \%)$ com filhos. Não se observou diferença significativa entre os sexos tanto no que diz respeito ao estado conjugal $\left(\mathrm{X}^{2}\right.$ $(1)=1,54 ; P=21,3 \%)$, quanto à existência de filhos $\left(X^{2}(1)=0,657 ; P=41,7 \%\right)$. A interferência da doença na vida afetiva / sexual foi relatada por $17(21 \%)$ dos pacientes, sem diferença significativa entre os sexos $\left(X^{2}(1)=0,628 ; P=42,8 \%\right)$.

A ajuda na resolução de problemas sociais foi solicitada espontaneamente por $33(41 \%)$ dos pacientes, referindo-se sempre a aspectos profissionais. Por outro lado, a opção pelo seguimento psicoterapêutico oferecido pelos autores foi feita por $66(82,5 \%)$ pacientes, sem diferença significativa entre sexos $\left(X^{2}(1)=0,066 ; P=79,7 \%\right)$.

Tabela. Alguns dados ilustrativos da realidade vivida pelos pacientes adultos com anemia falciforme seguidos regularmente no Hemocentro da UNICAMP.

\begin{tabular}{lccc}
\hline Dados sobre os pacientes & $\begin{array}{c}\text { Mulheres } \\
(n=49)\end{array}$ & $\begin{array}{c}\text { Homens } \\
(n=31)\end{array}$ & $\begin{array}{c}\text { Total } \\
(n=80)\end{array}$ \\
\hline A doença prejudicóu a escolarização & $16(32,6 \%)$ & $7(22,5 \%)$ & $23(28,7 \%)$ \\
A doença interfere na profissão & $28(57 \%)$ & $22(71 \%)$ & $50(62,5 \%)$ \\
Dependência financeira total & $40(81,6 \%)^{*}$ & $10(32,2 \%)$ & $50(62,5 \%)$ \\
Casados ou amasiados & $21(42,8 \%)$ & $9(29 \%)$ & $30(37,5 \%)$ \\
Casados ou amasiados com filhos & 14 em $21(66,6 \%)$ & $8 \mathrm{em} 9(88,8 \%)$ & 22 em $30(73,3 \%)$ \\
A doença interfere na vida afetivo/sexual & $9(18,3 \%)$ & $8(25,8 \%)$ & $17(21 \%)$ \\
Auto-imagem negativa & $7(14,2 \%)$ & $5(16,1 \%)$ & $12(15 \%)$ \\
Necessidade de orientaçăo social & $22(44,9 \%)$ & $11(35,4 \%)$ & $33(41 \%)$ \\
Opção pelo seguimento psicoterapêutico gratuito & $40(81,6 \%)$ & $26(83,9 \%)$ & $66(82,5 \%)$ \\
Conhecimento insatisfatório sobre a própria & $24(48,9 \%)$ & $19(61,3 \%)$ & $43(53,7 \%)$ \\
doença & & &
\end{tabular}

Observação: * indica diferença significativa entre os sexos $(P<0,05)$. 
Levando-se em conta um conjunto de variáveis, como o conhecimento do nome da doença, seu caráter hereditário e os objetivos do tratamento, pôde-se considerar o nível de conhecimento dos pacientes sobre a sua própria doença insatisfatório em $53,7 \%$ dos casos, sem diferença significativa entre os sexos $\left(\mathrm{X}^{2}(1)=1,158 ; \mathrm{P}=28,2 \%\right)$. Uma vã esperança de cura, por exemplo, foi constatada em 39 (49\%) pacientes (19 homens e $20 \mathrm{mu}$ lheres), sem diferença significativa entre os sexos $\left(\mathrm{X}^{2}(1)=3,18 ; \mathrm{P}=7,4 \%\right)$.

\section{Discussáo}

Ao discutir os aspectos de saúde pública da anemia falciforme que podem ser extraídos da realidade vivida pelos pacientes entrevistados, o primeiro problema a ser ressaltado, e talvez o mais importante, é o do diagnóstico tardio de uma doença congênita. De fato, comparando-se a idade dos pacientes com o tempo de estabelecimento do seu diagnóstico, é fácil deduzir que o mesmo foi reconhecido, na maioria deles, na adolescência ou no início da idade adulta. O problema assume proporções mais sérias quando se pondera que os pacientes que constituíram a casuística examinada no presente trabalho tiveram a oportunidade de atravessar a barreira seletiva da infância, uma vez que muitos brasileiros com anemia falciforme ainda falecem antes dos dez anos de idade. De fato, de acordo com $\mathrm{Hutz}^{7}$, a sobrevivência média do brasileiro com anemia falciforme é de 16,4 $\pm 12,1$ anos. Casuísticas significativas de crianças com anemia falciforme em acompanhamento médico regular só são observadas nos serviços pediátricos de alguns poucos hospitais universitários brasileiros, mormente naqueles que possuem um setor de hematologia infantil. No entanto, mesmo nesses serviços, o aspecto assistencial do aconselhamento genético dos pais dessas crianças, que apresentam o risco de $25 \%$ de gerar outros filhos com a mesma doença, nem sempre é valorizado. Além disso, os programas de diagnóstico neonatal da anemia falciforme, visando o início do tratamento antes dos 6 meses de idade, são excepcionais no Brasil12,13.

Dados da literatura internacional mostram que o diagnóstico precoce, sobretudo ao nascimento, e o tratamento adequado melhoram drasticamente a taxa de sobrevivência e a qualidade de vida dos doentes com anemia falciforme ${ }^{16,17,21}$. O simples esquema de vacinação, sobretudo contra o pneumococo e o Haemophilus influenzae, acompanhado de penicilinoterapia profilática, diminui 0 número de mortes no período crítico situado entre os 6 meses e os 3 anos de idade, época em que, pelas suas características imunológicas, o paciente falciforme é particularmente sensivel às septicemias fulminantes por bactérias encapsuladas ${ }^{17}, 21$. Nesse aspecto, o aconselhamento genético não diretivo dos pais de crianças com a anemia falciforme, mesmo que não altere as suas decisões reprodutivas, poderá atingir um outro importante objetivo médico: o de alertá-los para a importância do diagnóstico neonatal de outros filhos que venham a ter.

Ressalte-se o caráter assistencial, não diretivo, que deve ter o processo de aconselhamento genético, cujo único objetivo é possibilitar aos casais, com risco de gerar uma criança com a anemia falciforme, a tomada de decisões conscientes e equilibradas a respeito da procriação. As pretensões eugênicas dos primeiros programas populacionais de triagem da hemoglobina $S$, como os implantados nos EUA na década de 70, que visavam a obter, através do aconselhamento genético dos heterozigotos, um decréscimo significativo da incidência de homozigotos, podem ser hoje consideradas ingênuas ${ }^{3,14}$.

O diagnóstico laboratorial da anemia falciforme ao nascimento deve ser feito, de preferência, por técnicas sensíveis de eletroforese de hemoglobinas devido à presença, nessa época da vida, de alta percentagem de hemoglobina fetal no sangue ${ }^{13}$. No entanto, solução prática e econômica que vem sendo apontada por um dos autores do presente trabalho, desde a década de 70 (Ramalho ${ }^{12}$ ), é a inclusão da pesquisa da hemoglobina $S$ dentre os exames de rotina das gestantes brasileiras, o que pode ser feito por testes de solubilidade, que são exames simples que utilizam reagentes baratos e não exigem qualquer aparelhagem especializada ${ }^{8,9}$. Dessa forma, 0 exame eletroforético do sangue do recém-nascido, que pode inclusive ser feito com amostra de sangue do cordão umbilical, ficará restringido aos filhos das heterozigotas com o traço falciforme, já que essa é uma das condições genéticas indispensáveis para o nascimento de uma criança homozigota com anemia falciforme.

A alta taxa de desinformação sobre a doença, por parte dos pacientes, pode ser atribuída ao seu baixo nível de escolarização, relacionado, por sua vez, ao seu baixo nivel socioeconômico. Da mesma forma, a interferência relativamente pequena da doença na escolarização pode ser atribuída, fundamentalmente, à baixa solicitação do seu meio social, no qual o estudo não é valorizado. De fato, o índice de analfabetos na amostra de pacientes foi menor que o observado pelo IBGE em 1987, na região Sudeste do Brasil, onde $19,7 \%$ da população geral adulta era composta de analfabetos. Já nos EUA a anemia falciforme interfere significativamente na escolarização dos pacientes, pelo absenteísmo escolar decorrente das crises dolorosas 
e das hospitalizaçס̃es ${ }^{10}$. Cumpre enfatizar que o baixo nivel socioeconômico não é uma característica limitada à amostra de falcêmicos entrevistados no presente trabalho, sendo observada na maioria dos brasileiros com essa condição clínica, o que os torna mais dependentes dos serviços públicos de assistência à saúde ${ }^{7,13}$.

A interferência da doença assume, no entanto, caráter mais preocupante no que se refere à vida profissional dos pacientes. De fato, $57 \%$ dos entrevistados são inativos ou exercem atividades não remuneradas. Em levantamento realizado em $\mathrm{Cu}$ ba, em uma amostra de 84 pacientes adultos, apenas $26 \%$ não trabalhavam regularmente ${ }^{18}$. Essa diferença significativa $\left(X^{2}(1)=16,55 ; P<0,1 \%\right)$ talvez possa ser atribuída à existência, naquele país, de um programa de orientação do doente falciforme, com sua colocação profissional em atividades compativeis com a doença.

As constantes crises de dor, as internações hospitalares e as consultas médicas interferem na vida profissional de grande parte dos pacientes entrevistados, afetando de forma semelhante ambos os sexos. Cabe aqui salientar que Damlouji e col. ${ }^{4}$ consideram a situação financeira precária e a dificuldade em conseguir emprego como as principais causas do aparecimento de estados depressivos nos falcêmicos adultos.

Enfatiza-se, no entanto, que quase a metade do grupo pesquisado encontrava-se em situação de emprego regular e que a dependência financeira total foi observada apenas em um terço dos pacientes do sexo masculino, apesar da inexistência na comunidade de um programa de apoio e orientação profissional a esses doentes. Isso mostra a viabilidade de os pacientes falcêmicos poderem participar do mercado de trabalho, desde que estejam sob tratamento médico e exerçam funçōes compativeis com as suas limitaçōes e potencialidades. De fato, em $41 \%$ dos pacientes da amostra constatou-se a necessidade de orientação em nível de proteção no trabalho, recursos previdenciários e sociais. Foi surpreendente também a alta taxa de aceitação ao seguimento psicoterapêutico gratuito oferecido pelos autores do presente trabalho, sem diferença significativa entre os sexos. Tais dados enfatizam que mesmo os pacientes adultos com anemia falciforme, que recebem atendimento médico adequado, têm as suas expectativas voltadas para o lado social e psicológico, ansiando por obter independência econômica, emprego regular e pela possibilidade de casarem e terem filhos. Assim sendo, os programas de assistência a esses doentes devem prever, além do tratamento médico, a orientação psicossocial necessária ao desenvolvimento do seu potencial de integração à sociedade.
A interferência da anemia falciforme na vida afetiva-sexual, admitida por apenas um quinto dos pacientes é, por motivos óbvios, mas difícil de ser avaliada. A proporção de pacientes solteiros foi bem superior a de casados ou amasiados, mas é possível que isso esteja relacionado à preponderância da faixa etária mais jovem. $O$ fato de $37 \%$ dos pacientes serem casados ou amasiados, $74 \%$ dos quais com filhos, é bastante significativo, desmentindo a crença muito difundida entre os médicos brasileiros de que raramente o homozigoto com a anemia falciforme chega a se reproduzir.

Os dados do presente trabalho enfatizam, portanto, a necessidade da implantação de programas comunitários de diagnóstico precoce e de orientação médica, genética, social e psicológica dos doentes com a anemia falciforme no Brasil, modificando favoravelmente a realidade vivida pelos brasileiros com tal condição clínica. Torna-se pertinente questionar, por outro lado, a validade dos programas de diagnóstico pré-natal da anemia falciforme, visando o abortamento "terapêutico" dos casos afetados, que vêm sendo estimulados em alguns países, como é o caso, por exemplo, de $\mathrm{Cuba}^{6,18}$. Essa dúvida é compartilhada em nível internacional por grandes autoridades no assunto, tais como Bowman ${ }^{3}$.

\section{Agradecimentos}

Aos pacientes, médicos e funcionários do Hemocentro da UNICAMP que, com a sua inestimável colaboração, permitiram a realização do presente trabalho.

PAIVA e SILVA, R. B. de et al. [The sickle cell disease as a Public Health problem in Brazil]. Rev. Saúde Pública, 27: 54-8, 1993. Sickle cell anemia is the most prevalent hereditary disease in Brazil. However, the Brazilian literature registers no investigations into the public health aspects of the disease. This present study investigates the way of life of 80 adult patients ( 49 women and 31 men) with a diagnosis of sicklecell anemia, at a blood center in Brazil. The late diagnosis of the disease was one of the most significant aspects observed in this group of patients. It was also observed that the dominant problem faced by adult patients with sickle cell anemia is of an economic nature, mainly due to lack of professional opportunities. However, patients can well undertake economic activities under adequate medical supervision, according to their own limitations and potentialities. The psychoterapeutic orientation was well accepted by patients regardless of sex. It is concluded that there exists need for the establishment of community programs for early diagnosis and medical, social and psychological orientation for sickle cell anemia patients in Brazil.

Keywords: Anemia, sickle cell, epidemiology. Life quality. 


\section{Referências Bibliográficas}

1. ARAUJO, J. T. Geographical distribution and incidence of hemoglobins in Brazil. In: Inter-American Symposium on Hemoglobins: Genetic, Functional and Physical Studies on Hemoglobin, $1^{\text {st }}$,Caracas, 1971. Proceedings. Basel, Karger, 1971.

2. BEIGUELMAN, B. Curso prótico de bioestatística. $2^{2}$ ed. Ribeirão Preto, Ed. Soc. Bras. Genética, 1991.

3. BOWMAN, J. E. Prenatal screening for hemoglobinopahies. Am. J. Hum. Genet., 48: 433-8, 1991.

4. DAMLOUЛ, R. F. et al. Social disability and psychiatric morbidity in sickle cell anemia and diabetes patients. Psychosomatics, 23: 925-31, 1982.

5. FORATTINI, O. P. Epidemiologia geral. São Paulo, Ed. Artes Médicas, 1986.

6. GRANDA, $\mathrm{H}$. et al. Cuban programme for prevention of sickle cell disease. Lancet, 1: 152-3, 1991.

7. HUTZ, M. H. História natural da anemia falciforme em pacientes da região metropolitana do Rio de Janeiro. Porto Alegre, 1981. [Tese de Doutoramento - Instituto de Biociências da UFRGS].

8. ITANO, H. A. Solubilities of naturally occuning mixtures of human hemoglobin. Arch. Biochem., 47: 148, 1953.

9. LOUDERBACK, A. L. et al. Clinical evaluation of a rapid screening test for sickle cell trait (S -) and sickle cell anemia (SS). Clin. Chem., 20: 761-5, 1974.

10. MANKAD, V. N. School problems in sickle cell disease. Mobile Comprehensive Sickle Cell Center, University of South Alabama College of Medicine, 1991.

11. NAOUM, P. C. et al. Hemoglobinopatias no Brasil. Bol. Soc. Bras. Hematol. Hemoter., 8: 180-90, 1986.
12. RAMALHO, A. S. et al. Hemoglobina $S$ em recémnascidos brasileiros. J. Pediat., 41: 22-6, 1976.

13. RAMALHO, A. S. As hemoglobinopatias hereditárias: um problema de saúde pública no Brasil. Ribeirão Preto, Ed. Soc. Bras. Genética, 1986.

14. REILLY, P. Genetics, law and social policy. Cambridge, Harvard University Press, 1977.

15. SALZANO, F. M. \& TONTO, C. V. Hemoglobin types in Brazilian populations. Hemoglobin, 6: 85-90, 1982.

16. SERJEANT, G. R. The clinical features of sickle cell disease. Amsterdam, North-Holland, 1974.

17. SERJEANT, R. G. The sickle cell disease. Oxford, Oxford Medical Publications, 1985.

18. SVARCH, E. et al. Resultados delos estudios realizados in Cuba sobre la hemoglobinopatia S. Sangre, 36: 37-42,1991.

19. TRINCA, W. Diagnóstico psicológico: prática clínica. São Paulo, Ed. Pedagógica e Universitária, 1984.

20. VAVASSEUR, J. A comprehensive program for meeting psychological needs of sickle cell anemia patients. $J$. Natl. Med. Ass., 67: 335-9, 1977.

21. VICHINSKY, E. et al. Newbom screening for sickle cell disease: effect on mortality. Pediatrics, 81: 749-55, 1988.

22. WHITTEN, C. F. \& FISCHOFF, F. Psycosocial effects of sickle cell disease. Arch.Inter.Med., 133:681-9, 1974.

23. ZAGO, M. A. \& COSTA, F. F. Hereditary hemoglobin disorders in Brazil. Trans. R. Soc. Trop. Med. Hyg., 79: 385-8, 1985.

24. ZAGO, M. A. et al. Enfermidades drepanociticas en una población brasileña. Sangre, 28: 191, 1983.

Recebido para publicaçāo em 07.10.1992 Aprovado para publicação em 21.12.1992 